\title{
Effect of Work Performance on Global Functioning of Persons with Mental Illness Receiving Psychiatric Rehabilitation Services at a Tertiary Neuro-psychiatric, Super-Speciality Hospital at Bangalore, India: A Pilot Study
}

\author{
Sailaxmi Gandhi · Jagadisha Thirthalli • Poornima Bhola • B. P. Nirmala • \\ Premalatha Chinnayya · Rathnamma Laxmappa - Sivakumar Thanapal • \\ Avinash Waghmare - Santosh K. Chaturvedi
}

Received: 27 February 2014/Revised: 28 March 2014/Accepted: 8 April 2014/Published online: 29 May 2014

(C) Springer India Pvt. Ltd. 2014

\begin{abstract}
Psychiatric rehabilitation can help in making significant changes in all the spheres of functioning. A preexperimental design was selected to invite four male and one female patient to pilot test a rehabilitation model wherein supported work was offered by the treating facility. There was increase in mean work performance on the Griffith's scale as well as mean social, occupational functioning and symptom reduction on the MIRECC GAF scale after six months when compared to baseline values. When work performance increased, there was significant $(\Upsilon=0.932, \mathrm{p}=0.021)$ decrease in symptoms. This pilot study may help pave the way to recovery for patients with mental illness.
\end{abstract}

S. Gandhi $(\bowtie) \cdot$ P. Chinnayya $\cdot$ R. Laxmappa

Department of Nursing, National Institute of Mental Health \& Neurosciences, Institute of National Importance, Hosur Road, Bangalore, Karnataka 560029, India

e-mail: sailaxmi63@yahoo.com

J. Thirthalli - A. Waghmare $\cdot$ S. K. Chaturvedi

Department of Psychiatry, National Institute of Mental Health \& Neurosciences, Institute of National Importance, Bangalore,

Karnataka, India

P. Bhola

Department of Clinical Psychology, National Institute of Mental Health \& Neurosciences, Institute of National Importance,

Bangalore, Karnataka, India

B. P. Nirmala

Department of Psychiatric Social Work, National Institute of Mental Health \& Neurosciences, Institute of National

Importance, Bangalore, Karnataka, India

S. Thanapal

Department of Neuro Rehabilitation \& PRS, National Institute of Mental Health \& Neurosciences, Institute of National Importance, Bangalore, Karnataka, India
Keywords Psychiatric rehabilitation - Work performance $\cdot$ Global functioning $\cdot$ Recovery

\section{Introduction}

Psychosocial rehabilitation is a therapeutic approach that encourages a mentally ill person to develop his or her fullest capacities through learning and environmental support [1]. Although psychiatric treatment focuses on symptom reduction, rehabilitation focuses on all the domains of global functioning such as occupational, social, symptomatic functioning including work performance. Psychiatric rehabilitation can help in making significant changes in all the spheres of functioning. The researchers were interested in pilot testing a model wherein the psychiatric hospital where treatment was offered to patients with psychiatric disabilities would also offer supported employment as a form of psychiatric rehabilitation.

\section{Methods}

Aim

To pilot test a model of psychiatric rehabilitation wherein supported employment is offered by the treating facility.

Objectives

1. To evaluate the effect of work performance on global functioning of the patients receiving psychosocial rehabilitation services

2. To assess the relation between occupational functioning, symptomatic functioning, social functioning and work performance 
Hypotheses

H1 There will be a significant change in global functioning of patients with mental illness following implementation of the model

H2 There will be a significant relation between occupational, symptom and social functioning and work performance

This study was conducted in a psychiatric rehabilitation services setting which was part of a tertiary super-speciality psychiatric hospital at Bangalore, India. Around 60-70 patients of both genders (both out patients as well as in-patients) avail rehabilitation services from $9 \mathrm{AM}$ to 4 PM on all days except holidays. They are placed in sections of their choice and based on their interest, capacity, potential and future plans. There are various sections such as tailoring, computer, bakery, candle, mat weaving, plastic moulding, carpentry, leather, weaving, domestic, recreation and horticulture. A pre-experimental research design was used to invite five patients who were availing psychiatric rehabilitation services during the period February, 2012 to July, 2012. Both gender patients who were regularly attending the psychiatric rehabilitation services for more than a month and were either asymptomatic or able to work in the sections despite their symptoms were selected using non probability purposive sampling technique. These patients were being rehabilitated in a structured, supervised environment in the candle/tailoring/ leather/craft sections. Ethical clearance was obtained from the institute review board. The patients and their families were assured confidentiality and anonymity. Following informed consent from their family members as well as the patients themselves, after the baseline assessment, with approval from the administration, the patients were shifted to the hospital's dietary, laundry, swachaththa (cleaning) agency and horticulture work places. Supervisors and coworkers in these work places were approached and sufficient information was given about the patients' strengths and concerns. After a period of six months, a follow up assessment was done.

\section{Instruments}

A socio-demographic profile was prepared and used to collect data such as gender, age, education and diagnosis. The Mental Illness Research, Education, and Clinical Center (MIRECC) version of the Global Assessment of Functioning (GAF) scale (Niv, Cohen, Sullivan \& Young, 2007) was used to collect data about the patients' symptomatic, social and occupational functioning. Lower scores in a domain indicate more impairment in that domain, while higher scores indicate higher social and occupational functioning and reduced symptoms. The occupational and symptom subscales have good convergent and discriminant validity. The social subscale was related to measures of social functioning and, to a greater degree, symptom severity. The occupational and social subscales significantly predicted their respective domains at the nine-month follow-up. The symptom subscale predicted negative symptoms at follow-up; however, it did not predict positive symptoms or cognitive disorientation. Instead, the social subscale was predictive of cognitive disorientation at follow-up. All the three subscales of the MIRECC GAF have high reliability and good convergent as well as predictive validity [2]. There are other scales to measure global functioning such as the Global Assessment of Functioning (GAF). However, one major limitation of the GAF is that it combines three domains of functioning-occupational, social, and psychological-which do not always vary together [3]. The Social and Occupational Functioning Assessment Scale (SOFAS) is designed to measure social and occupational functioning without the influence of psychiatric severity and has similar limitations as the GAF [4]. Hence, the researchers preferred to use the MIRECC GAF. The 25 item Griffiths Work Behavior Scale is used to assess work skills [5]. Higher scores indicate higher work performance. The scale measures job skills' using bipolar statements such as 'grasps instructions quickly' versus 'cannot grasp instructions'. Each item is rated on a five point scale ranging from one - the least desirable to five - the most desirable rating. The Griffiths scale was developed using a sample of persons with severe psychiatric disability. The measure has demonstrated adequate validity and reliability including inter-rater reliability ranging between .70 to .84 (using the Spearman rho) and test re-test reliability of .75 . In terms of predictive validity, the scale was able to differentiate employed from unemployed subjects $(\mathrm{t}=10.2$, df $=26$, $\mathrm{p}<0.001)$ [6].

\section{Analysis}

Data obtained was analysed using sPSs 16 with descriptive statistics, t test, pearsons correlation coefficient \& Wilcoxon signed rank test. It was decided that $\mathrm{p}<0.05$ would be used to test significance levels.

\section{Results}

\section{Descriptives}

The mean age of the patients was $35.6 \pm 9.2$ and ranged from 27 yrs. to 50 yrs. While $80 \%$ (4) of them were males, 
$80 \%$ (4) were single, $60 \%$ (3) had attained primary education, the rest $20 \%$ (1) high school and $20 \%$ (1) graduate. $40 \%$ (2) had mild mental retardation, $40 \%$ (2) moderate mental retardation with seizures and $20 \%$ (1) had paranoid schizophrenia.

\section{Work performance}

The patients mean work performance measured with the Griffith's scale, while they were working in the different sections within the rehabilitation facility was $107.60 \pm 10.31$. After six months of working as part of the hospital workforce, their mean work performance increased to $113.60 \pm 11.04$. Although there was an increase in the work performance, this was not significant $(\mathrm{p}=0.138)$ (Table 1).

\section{Global functioning}

There was an increase in mean occupational functioning from $70.00 \pm 14.14$ to $74.00 \pm 5.48$. There was also an increase in mean social functioning from $60.00 \pm 18.71$ to $82.00 \pm 13.04$ and increase in mean symptomatic functioning from $66.00 \pm 13.42$ to $70.00 \pm 10.00$ indicating a reduction in symptoms. However, Wilcoxon signed rank

Table 1 Comparison of pre and post intervention scores on the Work performance scale

\begin{tabular}{lllll}
\hline Variable & Work performance & $\mathrm{t}$ value & $\mathrm{df}$ & $\mathrm{p}$ value \\
\hline $\begin{array}{c}\text { Pre-assessment } \\
\text { Mean } \pm \text { SD }\end{array}$ & $107.60 \pm 10.31$ & -1.852 & 4 & 0.138 \\
$\begin{array}{c}\text { Post-assessment } \\
\text { Mean } \pm \text { SD }\end{array}$ & $113.60 \pm 11.04$ & & & \\
\hline
\end{tabular}

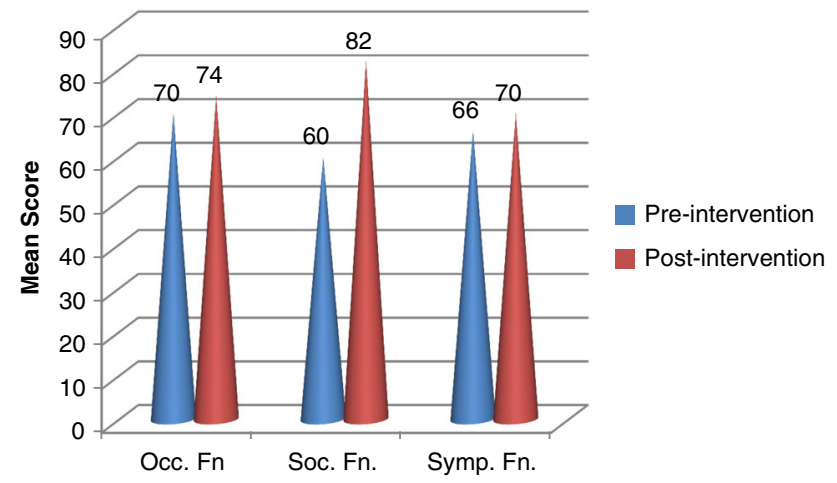

Fig. 1 Cone chart indicating the pre and post intervention scores on the MIRECC GAF scale test showed no significant change in symptomatic, occupational and social functioning (Fig. 1).

Work performance and global functioning

There was a significant positive correlation $(\Upsilon=0.932$, $\mathrm{p}=0.021$ ) between the patients' work performance and symptomatic functioning following change in nature of work. Although positive correlation was there between work performance and social as well as occupational functioning, it was not significant.

\section{Discussion}

The treating psychiatric hospital providing supported work for selected patients with their informed consent can be considered as a model of rehabilitation. Although it may not be possible to achieve complete cure, at least optimal functioning can be achieved.

Schmidt [7] in his article, 'A measurement of rehabilitation of psychiatric patients,' comments that in psychiatry, as in general medicine, a full restitutio ad integrum cannot be expected even after the most efficient treatment, although, functioning can fortunately be restored after the disease. In our study, of the five patients, four had mental retardation of varying severity and one patient had paranoid schizophrenia. Gopinath and Rao [8] while reviewing important world literature regarding psychiatric rehabilitation, had discussed the scenario in India and suggested steps to be taken to improve rehabilitation efforts in India.

In our study, although not significant, there was an increase in the domains of occupational and social functioning as well as a significant reduction in symptoms after six months of working in a supported environment along with hospital personnel. Either change of nature of work or the subjective feeling that they were now part of the workforce at the hospital had improved their global functioning.

In our study, with increase in work performance, there was significant reduction $(\Upsilon=0.932, \mathrm{p}=0.021)$ in symptoms. As well as providing evidence of the superiority of the individual placement and support (IPS) programme with regard to vocational outcomes, Burns et al. also found that participants who were employed for a minimum of 1 day showed more improvement in terms of clinical variables and subjective well-being than those who did not work [9]. Employment may lead to increased self-esteem and may ameliorate symptoms such as hearing voices because of the focus on work tasks and daily structure [10]. Most people with mental illness want to work and see 
finding employment as an important step towards recovery $[10,11]$.

\section{Limitations}

The subject group in our study was not a homogenous group. Four patients had mental retardation of varying severity while one had paranoid schizophrenia. There was only one female patient in this study. Small sample size, absence of randomization and control group were some more limitations in this study.

\section{Recommendations}

Further research could be done on employed patient satisfaction levels, families' perception of global functioning in patients following employment, different rehabilitation models, and qualitative research on colleagues and employers' perception of work output from patients with mental illness.

\section{Conclusion}

Further research in this area with larger sample size, control group and randomization may throw light on the durability and impact of this rehabilitation model. This pilot study may pave the way for persons on the road to recovery getting employed in the very facilities which treat them.
Acknowledgments The authors are grateful to the rest of the psychiatric rehabilitation services team including the subjects of this research who have contributed in many ways to this manuscript.

Conflict of interest There are no conflicts of interest.

\section{References}

1. Bachrach LL. Psychosocial rehabilitation and psychiatry in the care of long term patients. Am J Psychiatry. 1992;149:1455-60.

2. Niv N, Cohen AN, Sullivan G, Young AS. The MIRECC version of the global assessment of functioning scale: reliability and validity. Psychiatr Serv. 2007. doi:10.1176/appi.ps.58.4.529.

3. Goldman HH. Do you walk to school, or do you carry your lunch? Psychiatr Serv. 2005;56:419.

4. Kennedy JA, Foti ME. Axis V revisited. Psychiatr Serv. 2003;54:1413.

5. Griffiths A. A standardized assessment of work behavior. Br J Psychiatry. 1973;123:403-8.

6. Morisky DE, Green LW, Levine DM. Concurrent and predictive validity of a self-reported measure of medication adherence. Med Care. 1986;24:67-74.

7. Schmidt KE. A measurement of rehabilitation of psychiatric patients. Indian J Psychiatry. 1974;16:140-4.

8. Gopinath PS, Rao K. Rehabilitation in psychiatry: an overview. Indian J Psychiatry. 1994;36:49-60.

9. Burns T, Catty J, White S, Becker T, Koletsi M, Fioritti A, Rossler W, Tomov T, van Busschbach J, Wiersma D, Lauber C. The impact of supported employment and working on clinical and social functioning: results of an international study of individual placement and support. Schizophr Bull. 2008;35:949-58.

10. Strickler DC, Whitley R, Becker DR, Drake RE. First person accounts of long-term employment activity among people with dual diagnosis. Psychiatr Rehabil J. 2009;32(4):261-8. doi:10. 2975/32.4.2009.261.268.

11. Dunn EC, Wewiorski NJ, Rogers ES. The meaning and importance of employment to people in recovery from serious mental illness: results of a qualitative study. Psychiatr Rehabil J. 2008;32:59-62. 